\title{
ENGINEERING MANAGEMENT OF LIFELINE SYSTEMS UNDER EARTHQUAKE RISK
}

\author{
Hiroyuki KAMEDA ${ }^{1}$
}

\begin{abstract}
SUMMARY
The state-of-the-art of lifeline system management under earthquake risk is discussed. After a historical overview and specific features of lifeline earthquake engineering, elements of lifeline earthquake engineering practice are presented. They include outline of lifeline protection technologies, lessons from recent urban earthquakes particularly Kobe 1995, and seismic code developments. Then two topics are addressed specifically. First seismic reliability under system interaction is discussed with its general scheme and an analytical methodology. Next, criteria for lifeline performance is discussed with an emphasis on quantification of qualitative issues that are needed particularly in implementation processes. After presenting a general framework, two cases, one from Kobe on water customers' response, and one from California regarding funding procedure for seismic improvement. Finally, future orientations of earthquake engineering and its relation to lifeline earthquake engineering is addressed. It is emphasized that we should establish a third generation earthquake engineering where structural and geotechnical mitigation, crisis management, and sustainable development should be integrated through multi-disciplinary developments. Some examples of multi-disciplinary research initiatives are introduced.
\end{abstract}

\section{INTRODUCTION}

\subsection{Lifeline Earthquake Engineering - Historical Overview}

Under the worldwide trend of urbanization, earthquake protection of urban regions is a key issue. Conceptually, the target may be evaluated from the following two distinct points of view.

(1) Seismic safety of urban regions.

(2) Seismic reliability of urban regions.

The seismic safety is related to a state of being free from casualties and property losses, whereas seismic reliability stands for a state of being free from unacceptable loss of urban functions.

The major role of earthquake engineering in a traditional trend has been realization and enhancement of seismic safety. The research and technology developments have been focussed on structural and geotechnical issues to make engineered structures earthquake resistant through appropriate design and construction. Such definitive efforts have lasted for more than three quarters of this century. In the case of Japan, the development of modern earthquake engineering was initiated upon the experience of the devastating Kanto Earthquake of 1923, where it was demonstrated that seismic design is useful, effects of geotechnical conditions on ground motion intensity is important, etc. This aspect of earthquake engineering may be called "structural earthquake engineering."

Whereas seismic safety remains a major role of earthquake engineering, seismic reliability has grown an issue important as well in the recent decades. There are two principal reasons for this. (1) In the trend of growing urbanized societies, the requirements for high seismic reliability of urban functions under seismic risk has become a key issue. As modern urban functions rely on lifeline systems much more heavily than they used to, 
earthquake protection of lifelines systems is now a critical agenda for the enhancement of seismic reliability of urban regions. Indeed, lifeline systems are the only means to overcome potential inefficiencies of human activities in time and space caused by urban growth in size and complex activities. (2) Tremendous efforts concentrated on upgrading seismic safety have realized urban regions relatively safer than what they were before. This has made us observe cases in moderate earthquakes where lifeline systems are disrupted and greatly affect urban functions even when the safety issue is not thrown into catastrophic danger. This means that improvements in seismic safety has increased the importance of seismic reliability issue. These factors have led to the birth of a new branch of earthquake engineering called "lifeline earthquake engineering."

This notion was clearly recognized on the occasion of major earthquakes that took place in the 1970's. In the United States, the 1971 San Fernando Earthquake motivated the evolution of this new area, and the terminology "lifeline earthquake engineering" was proposed by US researchers, particularly under the leadership of late Prof. C. Martin Duke [Duke and Moran, 1975]. This movement, as well as the establishment of the Technical Council of Lifeline Earthquake Engineering (TCLEE) in ASCE, was responded spontaneously by Japanese researchers. The first US-Japan seminar on lifeline earthquake engineering was held in Tokyo in 1976, which was led by late Prof. Keizaburo Kubo [Kubo and Jennings, 1976].

Another epoch-making earthquake for the lifeline earthquake engineering developments was the 1978 Miyagiken-oki Earthquake, which damaged the City of Sendai and its vicinity, a central metropolis in northeastern Japan. This earthquake not only accelerated basic research of lifeline earthquake engineering but also motivated major lifeline sectors such as water, power and gas utilities, telecommunications, and transportation systems to actively participate in the research and development for earthquake protection and implement them in their own systems.

In China, the 1976 Tangshan earthquake was not only an overwhelming disaster to a densely populated urban region, but it has urged the development and implementation of modern earthquake engineering in the reconstruction of Tangshan. Development of lifeline earthquake engineering was certainly a major part, and it is being perused as a nation-wide issue [Sun, 1993].

The accomplishments of lifeline earthquake engineering have been tested in major earthquakes that followed, including 1983 Nihonkai-Chubu (Japan), 1985 Michoakan (Mexico), 1987 Chibaken-toho-oki (Japan), 1989 Loma Prieta (USA), 1990 Luzon (Phillipines), 1993 Kushiro-oki (Japan), 1993 Hokkaido-nansei-oki (Japan), 1994 Northridge (USA), 1995 Hyogoken-nanbu (Kobe) (Japan), etc. These earthquakes, on one hand, demonstrated the usefulness of lifeline earthquake engineering for the enhancement of urban seismic reliability. On the other hand, they posed new problems of lifeline studies that require further efforts which will be discussed in the following parts of this paper.

\subsection{Specific Features of Lifeline Earthquake Engineering}

The lifeline systems include:

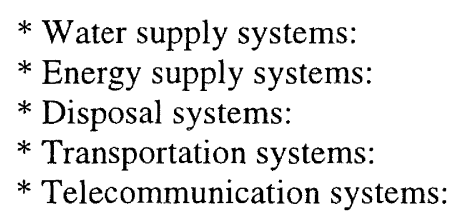

potable water and industrial water supply.

electric power supply, gas and oil supply, etc. sewer, garbage \& waste treatment, etc.

road \& highway traffic, railway, etc.

telephone, facsimile, digital data communication.

Because of system characteristics of lifelines that constitute a wide-spread and highly hierarchical networks, development of lifeline earthquake engineering has led to a unique set of earthquake countermeasures. The earthquake effects on lifeline systems involve not only earthquake resistant design and construction of their individual components, but also enhancement of system performance under earthquake emergency that are achieved by means of network redundancy, backup facilities, and effective post-earthquake recovery operations, which are to be followed by reconstruction and improvement to cope with the future earthquakes.

Lifeline systems are characterized by their wide spatial distribution. An entire lifeline system forms a network configuration that is composed of various types and a large number of link components and node components. Lifeline facilities must be constructed throughout their service areas regardless of the soil conditions of their sites. Because of the fact that many big cities and their metropolitan areas worldwide are situated in coastal zones and/or near river mouths and are inevitably subject to poor soil conditions due to soft sedimentary deposits, the lifeline systems serving such regions involve inherent vulnerability in terms of their seismic risk. 
Another aspect that are concerned with earthquake vulnerability of lifeline systems is that they generally constitute highly hierarchical systems. The hierarchical systems may be characterized as:

$\begin{array}{lll}\text { hierarchy level of components } & \text { high } & \text { low } \\ \text { number of facility units } & \text { small } & \text { large } \\ \text { effects of disruption } & \text { large } & \text { small }\end{array}$

Because of the large number of units and relatively lower effects of their disruption on the entire system functionality, it is often difficult, not feasible under economic constraint, to provide the components at a low hierarchy level, e.g., terminal water distribution network with small diameter pipes, with uniform earthquake resistance regardless of soil conditions, or high resistance same as that of other components at higher hierarchy levels.

The specific feature of lifeline systems characterized by their wide spatial distribution and their highly hierarchical system structure has led lifeline earthquake engineering to consist of the following major branches dealing with technologies for:

(1) enhancement of structural performance of individual lifeline components,

(2) seismic reliability management of lifeline networks, and

(3) methodological developments for efficient post-earthquake operations.

A comprehensive combination of the outputs from these branches is a distinctive feature of lifeline earthquake engineering, while other facilities like buildings, dams, bridges, etc. primarily rely on the technologies from structural earthquake engineering. Systematic observations of this aspect were made by many authors including Nojima, Kameda and Shinozuka [1990], and Kameda and Nojima [1992].

The research results have been presented not only in general earthquake engineering conferences, but also in conferences organized as continuing efforts specially for lifeline earthquake engineering. Major publications in this context include TCLEE / ASCE Conferences [TCLEE / ASCE, 1977, 1981, 1991, 1995 and 1999], USJapan Cooperative Research [Kubo and Shinozuka, 1981], US-Japan Panel Workshop [PWRI, 1984, 1989, 1992, 1995; NIST, 1984, 1991, 1997], US-Japan / Japan-US Workshops on Earthquake Resistant Design of Lifeline Facilities and Countermeasures against Soil Liquefaction [O'Rourke and Hamada, 1988, 1989, 1991, 1992, 1994, 1996, 1999] , China-Japan/ China-Japan-US Symposium on Lifeline Earthquake Engineering [Hu, Hou, Takada, Wang, 1990, 1994 and 1998], etc.

\section{ELEMENTS OF LIFELINE EARTHQUAKE ENGINEERING PRACTICE}

\subsection{Outline of Lifeline Protection Technologies}

On the basis of better understanding of seismic behavior of lifeline systems, earthquake countermeasures have been developed and implemented in actual systems by many lifeline sectors. Earthquake countermeasures for lifelines are aimed at abating outcome of an earthquake; specifically, they are (1) preventing and mitigating physical damage, (2) minimizing service malfunction, (3) mitigation of secondary disasters, and (4) executing an expeditious recovery.

To realize these objectives, various disaster mitigation measures have been established, which may be classified in the following four categories:

(1) upgrading structural performance of network components. pipelines, liquefaction, fault offset, structural interfaces

(2) improvement of network organization. redundant systems, fault-crossing elements

(3) implementing system automation.

UrEDAS, shutdown valves, automated backup generators

(4) disaster operation under earthquake emergency.

block separation systems, information management systems, monitoring systems, mutual-aid agreements, expert systems

On which categories of these four emphasis are placed depends on the system characteristics of individual lifelines. It is noted that the set of earthquake countermeasures are the consequences of basic studies in lifeline earthquake engineering as well as creative technology developments in the each lifeline sectors and related industries. Their typical examples are found in the development of ductile iron pipes with earthquake-proof joints, construction of redundant networks, zonal block separation for isolation of damaged networks, 
installation of earthquake monitoring for effective emergency shutdown and operation, implementation of expert systems to aid post-earthquake operation, etc.

Despite these accomplishments, there still remain many practical issues to be studied and incorporated in engineering practice. The following list was developed through discussion in a task committee by Kansai Chapter of the Japan Society of Civil Engineers (JSCE), entitled Committee on Lifeline System Interaction Studies and Development of Information Management System under Urban Earthquake (Chair: H. Kameda), whose summary is found in Kameda and Takada [1991].

(1) Problem arising form urbanization

*Increase in number and size of underground structures.

*Traffic congestion on major urban highways.

*Staff team organization under emergency with long commuting distance.

(2) Issues of hazard assessment

*Common basis for scenario earthquakes

*Method of reliable damage assessment

*Real-time microzonation by on-line monitoring

(3) Strategies of lifeline protections from earthquake

*Optimization based on hierarchical system characteristics

(4) System interactions between different lifelines

*Information sharing and total management

*Balanced preparedness among different systems

(5) Structural/geotechnical issues

*Liquefaction issues

*Diagnosis, retrofit and rehabilitation of aged systems

(6) Improvement of systems

*Larger supply stock

*More backup units and facilities

*Network redundancy

(7) Emergency response

*Safety of high-speed railways

*Implication to earthquake prediction

These items were not necessarily new problems in early 1990's when they were developed. Many efforts for research and implementation had already been made, and their accomplishments were significant. But these listings indicate that many lifeline engineers still thought that what had been achieved were not yet satisfactory for realizing an adequate level of urban seismic reliability. It proved to be right in the Great Hanshin-Awaji Earthquake Disaster of 1995.

\subsection{Lessons from Recent Urban Earthquake Disaster - Message from Kobe}

In this section, the lifeline performance under recent urban earthquakes is discussed. The 1995 Hyogoken-nanbu (Kobe) Earthquake is observed extensively, as its damage was far more severe than other recent urban earthquakes among modern metropolitan regions in developed countries.

The reason for such a big disaster in Kobe are understood as compound effects of very destructive near-field ground motions that were affected by its specific source mechanism, and vulnerability of existing lifeline facilities and operation systems. Detailed observation of these issues regarding civil infrastructure systems was made by Kameda and Hamada [1998].

Extensive studies have been performed regarding seismo-techtonic, engineering as well as socio-economic aspects of the Kobe disaster [e.g.,JSCE 1996b]. For information retrieval of documents, readers are referred to the following two activities, which are believed to offer most complete collection that are accessible from any individuals and organizations.

* Kobe University Library, The South Hyogo Earthquake Materials Collection (Kobe University Library, Rokkoudai, Nada, Kobe 657, Japan) Library home page: http://www.lib.kobe-u.ac.jp/e-index.html; NonJapanese materials list: http://www.lib.kobe-u.ac.jp/eqb/foreign.html, e-mail: shinsai@lib.kobe-u.ac.jp

* KOBEnet-Tokyo (KOBEnet, INCEDE, Institute of Industrial Science, University of Tokyo, 7-22-1, Roppongi, Minato-ku, Tokyo 106, Japan) Homepage: http://incede.iis.u-tokyo.ac.jp/kobenet/e-mail: kobenet@incede.iis.u-tokyo.ac.jp

The effects of the Hyogoken-nanbu Earthquake on lifeline system functions may be summarized as follows. 
(1) Damage was quantitatively very large. Utility service was disrupted at 1.2 million customers in water supply, 0.85 million in natural gas supply, and 2.6 million in power supply. Due to the collapse of access-controlled highway structures, an east-west corridor for a normal traffic volume of 250,000 vehicles/day was thrown into a serious congestion. Three commuter railways serving the Hanshin metropolitan region were heavily damaged causing difficulties to 600,000 passengers/day. Approximate number of pipe breaks in water supply systems was 3,600 in distribution mains and 134,000 in service pipes. Most of leaks in the natural gas supply system were observed in low-pressure pipelines, with 5,188 breaks in distribution mains and 21,669 in service and in-house piping.

(2) Extensive cascade effects and interactions were observed among different systems. It is well known that in destructive earthquake disaster, damage propagation is inevitable, especially in highly developed urban areas.

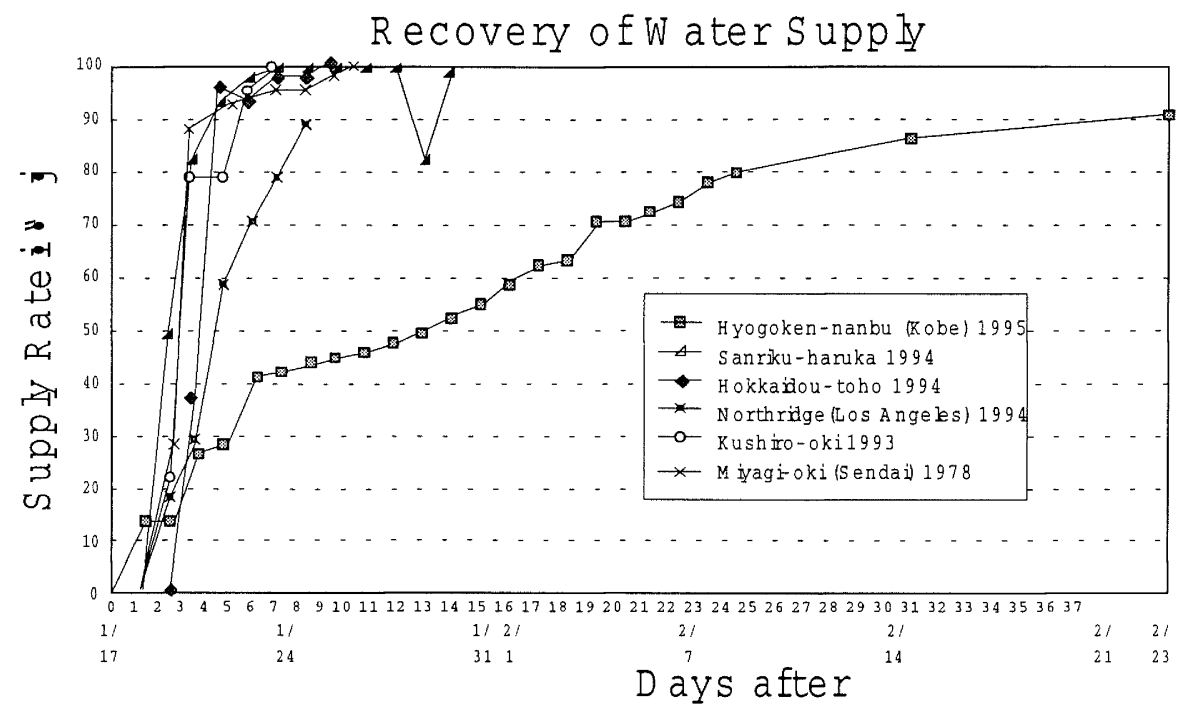

Figure 1: Functional restoration of water supply systems in recent urban earthquakes

Lifeline interactions unfortunately played a pivotal effect in disaster chain in the aftermath of the HanshinAwaji earthquake disaster. Interaction related problems are summarized in issues related to i) physical damage propagation, ii) functional damage propagation, iii) recovery interruption, iv) back-up functions of substitutive systems, and vi) compound damage propagation.

(3) Functional restoration required a very long period of time. Because of the extensive damage as described previously, restoration work for social infrastructure needed an enormous operation. In addition to the activities by the lifeline sectors directly in charge of the damaged systems, nation-wide operation aid teams were organized on the governmental as well as professional association bases. Yet the functional restoration needed much longer times, five - ten times, than those we experienced in recent major urban earthquakes, namely, 82 days for water supply, 85 days for natural gas supply, 7 days for power supply, 20 months for highway bridges, and 6 months for major lines of railways. As an example, Figure 1 compares the restoration curves for water supply systems in recent urban earthquakes. Quantitatively very long restoration period caused qualitatively very severe users' difficulties as will be discussed in a later chapter.

Despite difficult situations of long lasting lifeline disruption, there were important findings regarding lifeline earthquake engineering practice, which may be summarized as follows.

(1) Under this heavy structural and geotechnical failures of lifeline facilities, modern lifeline engineering technologies proved to be promising in various ways. High-performance pipes including steel pipes with modern butt welded joints and ductile-iron pipes with seismic joints performed well with no substantial leaks even in areas where extensive liquefaction-induced permanent ground displacement occurred, while old cast iron pipes broke easily even under relatively firm soil condition, see photographs in Figure 2. Development of modern earthquake engineering has, thus, proved to be in a right track.

(2) Methodologies of lifeline management under earthquake emergency were tested in the true earthquake event. Among them, emergency shut down valves installed in distribution tanks for the Kobe municipal water supply system functioned well, and reserved water of $40,000 \mathrm{~m}^{3}$ which was used for emergency delivery. Block separation system of the Osaka Gas Co. was activated to separate the heavily damaged area from areas with slight damage or no damage, which enabled the repair teams concentrated in the limited disaster area, while service was continued in the other areas around. These operational methods generally proved useful to meet earthquake disaster emergency needs. 
(3) In reconstruction of structures for civil infrastructure systems, efforts were taken to incorporate new visions to initiate the next generation of earthquake engineering technology. Highway bridge reconstruction was performed with a new design load to consider near field ground motions from intra-plate earthquakes. Some highway viaducts were reconstructed on the basis of comprehensive structural system design concepts with base isolation rather than component design of individual structural elements (Figure 3). Urban highways were rebuilt in a way to improve an environmental problem of noise from traffic vehicles (Figure 4). In reconstruction of harbor facilities for Kobe Port, strategic decisions were made to design liner berths at selected important locations for design seismic loads that are higher than the others. These experiences practiced in the reconstruction activities constituted bases for the seismic code revisions, retrofit of existing structures, and related activities that followed.
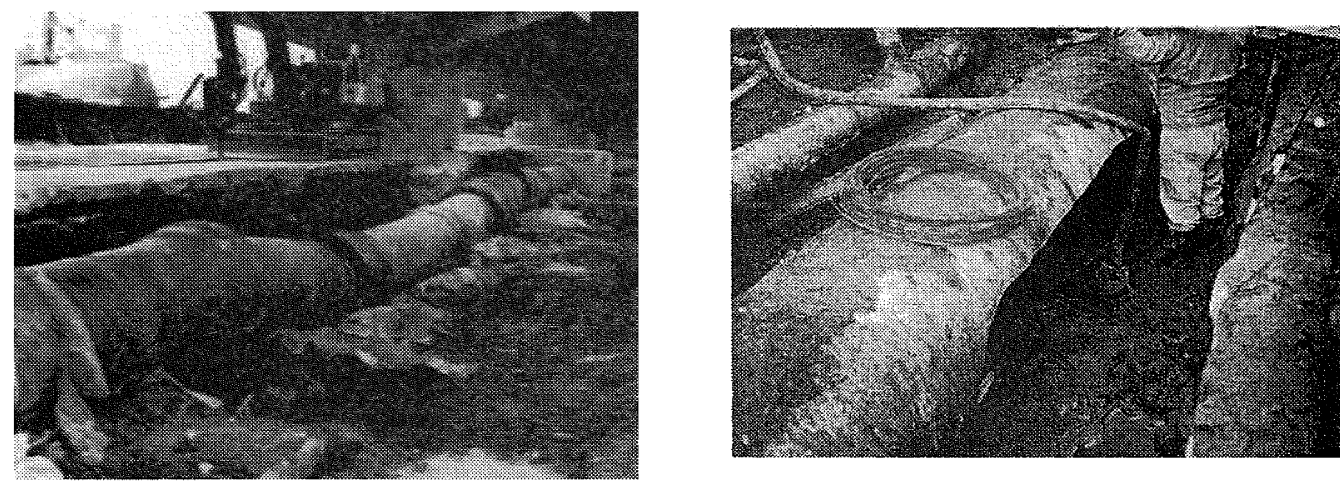

Figure 2: Buried pipelines under earthquakes - ductile iron pipes with seismic joints surviving large permanent ground deformation (left) and brittle failure of cast iron pipes (right)
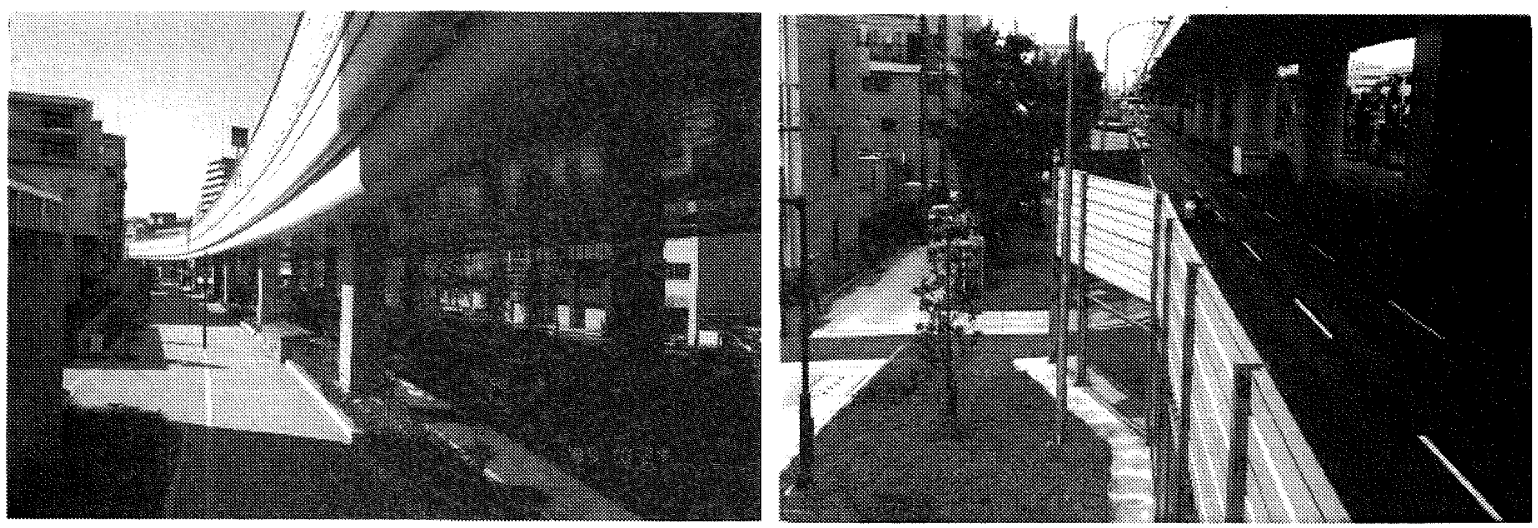

Figure 3: Nineteen-span continuous girder-frame Figure 4: New constructions for improvement of structure with base isolation at pier foot adopted for reconstruction of Benten viaduct in Kobe environmental problems from traffic noise adopted in reconstruction from disaster (Ashiya)

\subsection{Seismic Code Developments for Lifeline Systems}

The seismic codes for civil infrastructures including highway bridges, railway facilities water and sewer facilities, buried gas pipes and high pressure gas facilities were revised following the Hyogoken-nanbu (Kobe) Earthquake. The general concepts for these revisions reflect the JSCE Recommendations on Earthquake Resistance of Civil Engineering Structures [JSCE 1996a], which was proposed as the output from a Special Task Committee of Earthquake Resistance of Civil Engineering Structures organized in March 1995. Major decisions made in the code revisions have following common features.

(1) Two levels of earthquake motion, i.e., Level I and Level II design motions have been incorporated. In principle, the Level I motions account for moderate seismic loads experienced at sites from random sources, while the Level II motions stand for near field ground motions immediately from the causative fault. The Level II motion is to be determined directly from scenario mechanism of susceptible active faults. For the cases where the fault survey is difficult because of thick alluvial and diluvial deposits, standard Level II motions may be specified on the basis of recorded near-field ground motions.

(2) The concept of performance-based design and management has been adopted extensively. The importance of structures and facilities are classified into several categories, and required seismic performance is defined from the relation of ground motion levels and their probability of occurrence. 
(3) For the design against the Level II motion, it is basically required to estimate the plastic deformation and ultimate strength of structures including $\mathrm{RC}$ and steel structures as well as soil structures including embankments, quaywalls and foundations. Buried pipes in liquefiable grounds are subejected to $1.2-2.0 \%$ ground strain.

Table 1: Consideration of specific active faults in recent code revisions

\begin{tabular}{lll}
\hline Allow consideration of active faults explicitly? & Category & Revised in: \\
\hline "Yes" & $\square$ Railways & 1998 \\
Alternatives: & $\square$ Water & 1997 \\
(1)Active faults & $\square$ Sewer & 1997 \\
(2)Specified design spectra & $\square$ Port \& harbor & 1995 \\
\hline "No" & $\square$ Highways & $1996,(2000)$ \\
Specified design spectra (Kobe \& Kanto) & $\square$ Storage tanks & 1996 \\
\hline "No" & $\square$ Power & \\
Specified design spectra (Kanto) & $\square$ Gas supply & \\
& $\square$ Dams & \\
& $\square$ Buildings & $1995,(2000)$ \\
\hline
\end{tabular}

Thus, to consider specific active faults for Level II design is a new direction that emerged in the seismic codes of civil infrastructures. This does not necessarily mean that the scenario earthquake-based ground motions should be developed for each lifeline system. A better way is to generate hazard conditions for general regional disaster management plan uses, and apply them to lifeline system designs.

In doing so, ground motions should be generated by using most advanced simulation techniques that take into account the source mechanism such as asperity distributions and rupture propagation, source-to-site propagation effects for high frequency components by using semi-empirical methods, three dimensional topographical effects on low frequency components, nonlinear soil amplifications, quantitative evaluation of modeling uncertainties and uncertain parameter, etc. Such an example is found in Irikura [1998] with an application to Osaka basin. In this way, a definite orientation is perused for obtaining a common basis of science-based regional hazard assessment to cope with earthquake disasters caused by strong near-field ground motions under rupture of specific active faults, that are regarded as "low probability but high impact disaster."

As a matter of fact, there are differences in the ways this concept is incorporated among different lifeline facilities as shown in Table 1. This depends on the actual structural and system performance of lifelines under the Kobe disaster as particularly to how well their modern technology worked. The concept is already in practice, but its feasibility is not uniform throughout the country, depending on the tectonic characteristics and levels of information available. In the following paragraphs, two typical examples of code revisions, water supply systems and railway facilities, are introduced where advanced concepts have been perused intensively.

\section{(1) JWWA Guidelines for Water Supply Facilities}

The Japan Water Works Association (JWWA) revised its Seismic Design and Construction Guidelines for Water Supply Facilities [JWWA, 1997; Matsushita, 1999a]. General design flowchart is shown in Figure 5. Its specific features are characterized by the "importance level" and "system improvement" boxes.

System components are classified according to their importance levels A and B. Corresponding to each importance level, different performance requirements are specified for Level I and Level II design seismic loads, on which basis design calculations are executed The descriptions are such as "no damage" (A\&I), "functionality maintained under minor damage at individual components" (B\&I), "no serious threat to human life / functionality to be maintained under minor damage at individual components" (A\&II), and "functionality of entire system to be maintained with structural damage and malfunction at some individual components" (B\&II). It is also a feature of the JWWA guideline that options between structural improvement and network redundancy 


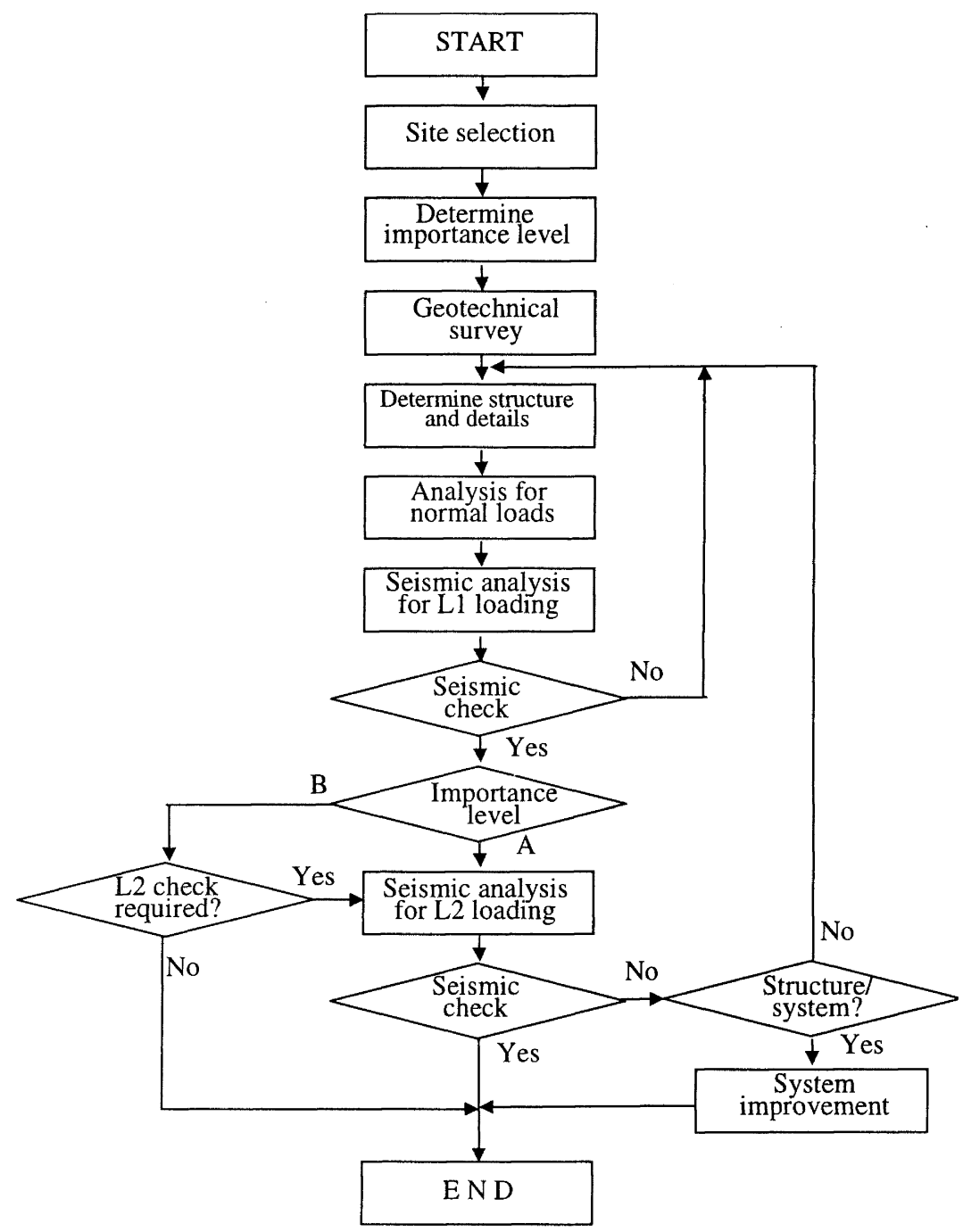

Figure 5: Seismic design procedure for water supply systems (JWWA, 1997 Guideline)

Design steps

Defining input earthquake motions

Evaluation of ground subsurface layers

Calculation of structural response

Check and evaluate structural performance
Time history dynamic analysis method

Non-linear spectrum method

Figure 6: Procedure of earthquake resistant design for railway structures [after Nishimura, 1999] 
enhancement are recognized to be equally feasible as means for realizing system performance requirements.

(2) Design Standards for Railway Structures

Another example is the new Earthquake Resistant Design Standards for Railway Structures, which became effective in December 1998 after a four-year activities based on comprehensive studies of the disaster in Kobe, research on structural and system response and failure under very strong near-field ground motions, theoretical as well as experimental [RTRI 1999, Nishimura 1999]. Its major feature may be recognized in its most advanced performance-based-design oriented format that have sound scientific and engineering bases.

Quantitative links are provided among (a) seismic load definition (Level I \& Level II), (b) structural and system performance requirements in three levels (PI, PII \& PIII), and (c) damage states corresponding to each performance level (structural member damage \& foundation stability). On this basis, the consistent design calculations and evaluations are conducted as shown in Figure 6. Structural responses are determined from dynamic analysis. Damage states and stability are evaluated from push-over analysis.

\section{SEISMIC RELIABILITY UNDER SYSTEM INTERACTIONS}

\subsection{Scheme of System Interactions}

It was pointed out in $\mathbf{2 . 2}$ that extensive cascade effects and system interactions occurred in the 1995 disaster in Kobe. Not only the case of Kobe, system interactions are a reality in many urban earthquakes. The interactions take place in various manner. On the basis of information from actual earthquake disaster, they can be shown in a form of "interaction matrix" indicating the relations between impacting and impacted systems [Kameda, 1994]. The system interactions that were observed in the Great Hanshin-Awaji (Kobe) Earthquake Disaster are found in Nojima and Kameda [1996]. On these bases, the system interactions can be categorized into four groups; i.e., (a) physical damage propagation, (b) functional damage propagation, (c) recovery interruption, and (d) back-up functions of substitute systems. These items are summarized in Table 2.

Table 2: Types of lifeline system interactions

\begin{tabular}{|c|c|c|}
\hline category of interaction & examples & countermeasures \\
\hline $\begin{array}{l}\text { a. physical damage } \\
\text { propagation }\end{array}$ & $\begin{array}{l}\text { *structural interaction in buried } \\
\text { pipelines } \\
\text { *structural interface }^{\text {* }} \\
\text { *crossing interface }\end{array}$ & $\begin{array}{l}\text { *common-purpose conduit } \\
\text { *interface adjusting pipe joint } \\
* \text { design of traffic crossing components }\end{array}$ \\
\hline $\begin{array}{l}\text { b. functional damage } \\
\text { propagation } \\
\text { (cascade effects) }\end{array}$ & $\begin{array}{l}\text { *power shortage causing } \\
\text { malfunctioning of other systems } \\
\text { *failure of water transmission causing } \\
\text { distribution disruption }\end{array}$ & $\begin{array}{l}\text { *backup, network redundancy } \\
\text { *structural enhancement of trunk lines }^{\text {s }}\end{array}$ \\
\hline c. recovery interruption & $\begin{array}{l}\text { *interaction between buried lifelines: } \\
\text { water-gas, power-water, } \\
\text { sewer-water, etc. }\end{array}$ & $\begin{array}{l}\text { *scheduling coordination } \\
\text { *network block isolation }^{\text {netwo }}\end{array}$ \\
\hline $\begin{array}{l}\text { d. back-up functions of } \\
\text { substitute systems }\end{array}$ & $\begin{array}{l}\text { *emergency power } \\
\text { *road traffic-railway ridership }\end{array}$ & $\begin{array}{l}*_{\text {network redundancy }} \\
*_{\text {emergency operation }} \\
*_{\text {rail-bus backup }}\end{array}$ \\
\hline
\end{tabular}

\subsection{Analytical Framework of Functional Damage Propagation}

As an example of seismic risk assessment of lifelines under system interaction, a multi-system seismic risk analysis is discussed. This corresponds to dealing with problems pertaining to Item b in Table 2 . The analytical procedure is schematically illustrated in Figure 7. It shows steps for risk assessment for a multiple system. Construction of event-trees of system interface in the stage of system modeling is a key step in dealing with system interactions.

As an illustrative example, seismic risk analysis for a water supply system linked with power supply was analyzed. Since electric power is essential to pivotal facilities of water supply systems, focus was placed on assessing and reducing the effect of loss of power supply. An illustrative example is shown in Figure $\mathbf{8}$ which is a plot of the probability of loss of water supply along a specific delivery path of pipelines. The horizontal axis is 
the distance from the water intake facility. "basic model" represents the overall seismic risk of loss of water supply in the original system state. It is generally observed that the probability of malfunction increases with the distance from the source node. However, the probability of malfunction at hierarchically lowest five nodes are seen to be particularly large. These five nodes are located on hillsides and they rely on a booster pump which require additional electric power for which the contribution of the probability of powr loss becomes very high.

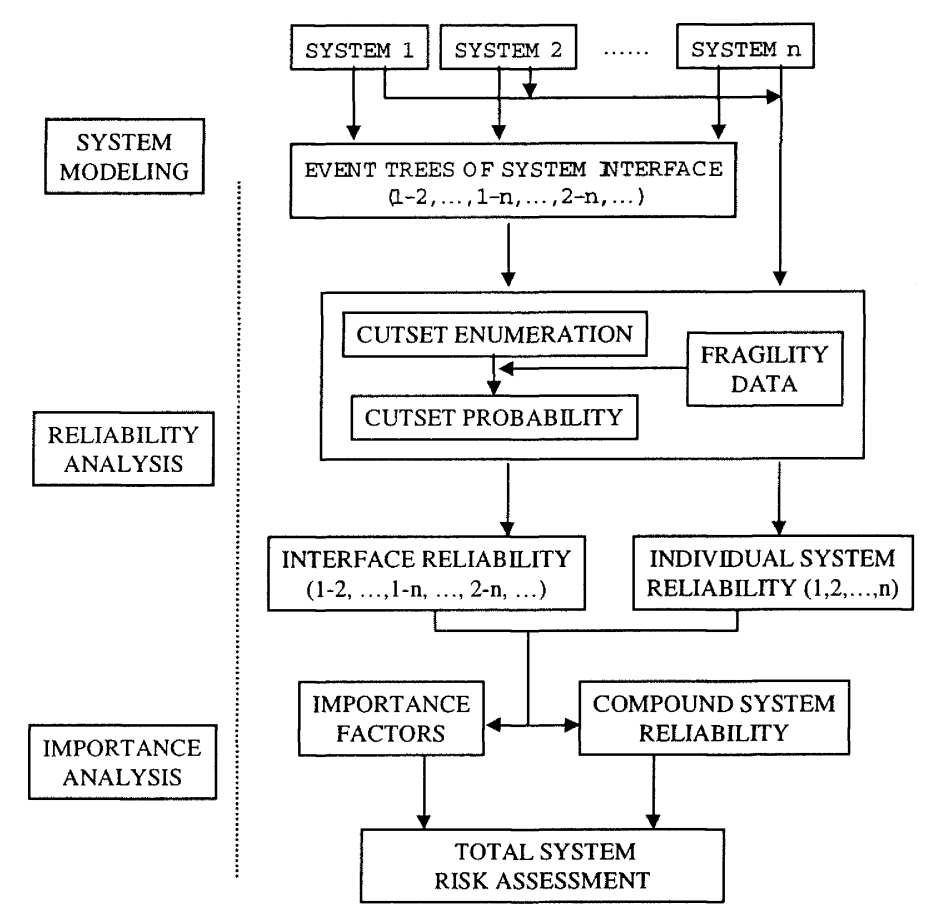

Figure 7: Flow chart of seismic risk analysis of lifelines under system interaction

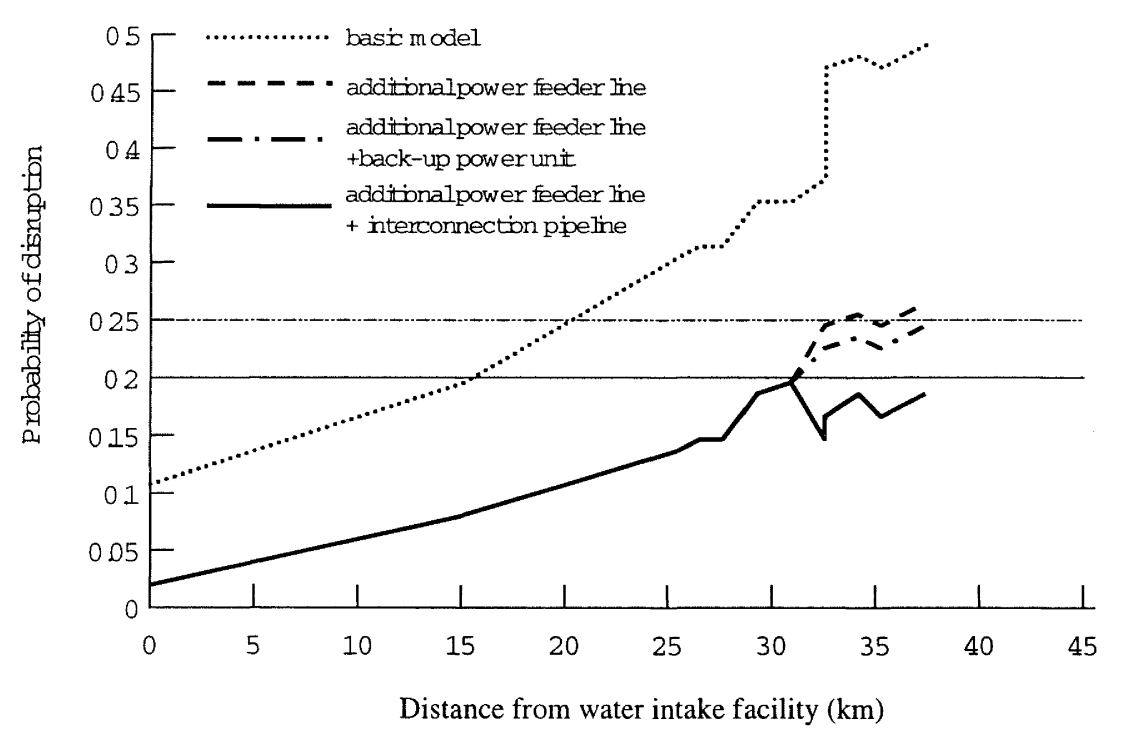

Figure 8: Probability of water supply system and its reduction measures (target levels: $G(P)=0.25,0.2$ )

In order to reduce the probability of malfunction of the water supply system, two kinds of measures against power failure were examined. One is (a) installation of additional power feeder line to reduce the probability of power failure, and the other is (b) installation of back-up power unit. Additionally, (c) construction of system interconnecting pipeline to upgrade network redundancy was considered. Figure 9 shows the effects of these 
measures on the improvement of system reliability. In this particular example, measure (a) and/or measure (b) are effective in reducing the risk to the level of 0.25 probability. If further risk reduction is needed, these countermeasures against power failure should be applied in combination with the measure (c) to improve the redundancy of the pipeline network.

\section{CRITERIA FOR LIFELINE PERFORMANCE SEISMIC RISK MANAGEMENT -QUANTIFICATION OF QUALITATIVE ISSUES-}

\subsection{General Framework of Lifeline Performance Criteria}

Figure 9 shows a general framework of post-earthquake performance of lifeline systems. The upper part of the figure is based on purely engineering aspect of performance evaluation. Figure 9(1) shows that structural performance of a group of a large number of components that constitute fine lifeline networks are evaluated by using fragility curves, while critical components should be evaluated by event tree-, fault tree- and reliability assessment for individual subsystems. For the post-earthquake recovery phase, Figure 9(2) shows that "restoration curves" are common tools for overall post-event system performance evaluation, and engineering measures for supply to critical facilities under earthquake emergency are key factors for dealing with specific lifeline components.

A practical criterion is how to minimize the area above the restoration curve within constraints of resources for post-earthquake activities. Optimization of functional restoration works in this context has been discussed [Isoyama et al, 1985; Nojima and Kameda, 1992] as part of efforts for research aimed at efficient lifeline recovery planning for post-earthquake periods.

(1) Component Performance
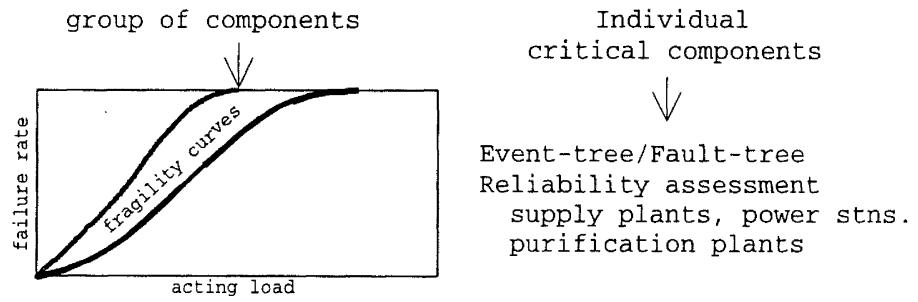

(2) System Performance
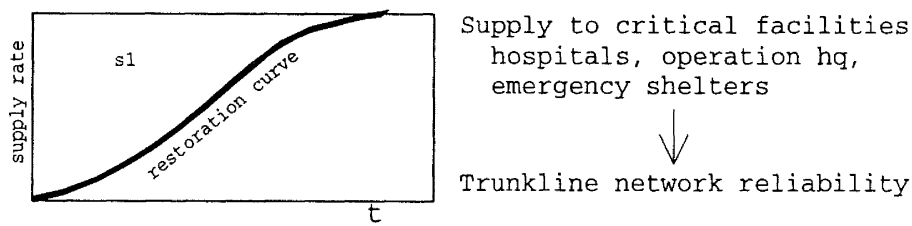

(3) Societal Performance

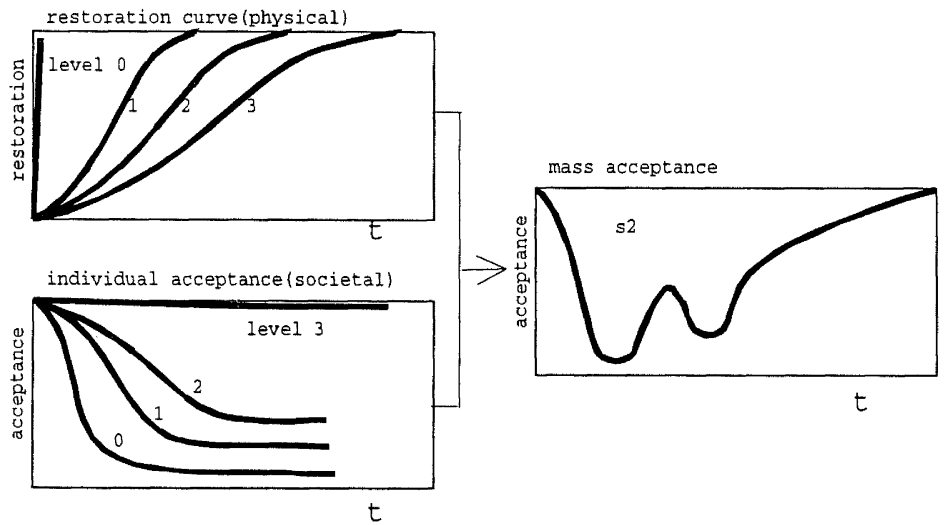

Figure 9: Performance of lifeline systems under earthquake environment 
It should be noted the target reliability for earthquake protection of lifelines cannot be determined only from engineering measures. Questions are often raised from engineers of lifeline sectors that a rational basis should be provided by which the post-earthquake performance of lifelines can be evaluated in a way that societal consensus or acceptance is realized. To do this, it is indispensable to incorporate evaluation of lifeline performance in an appropriate manner from the users' side.

Figure 9(3) is a conceptual illustration of a scheme to evaluate users' inconvenience under lifeline disruption [Kameda, 1994]. In this context, we also use restoration curves, but we need restoration curves for various levels of lifeline services. Conventional restoration curves are normally defined as the time variation of the proportion of the served section in the entire service area, where the situation is judged from "served" or "not served." It should be noted that considering different levels of service will lead to different restoration curves.

Consider a case of water supply. We may classify the levels of water supply into the following typical cases. (a) 3lpcpd (litters per capita per day) is specified as a minimum standard of water supply under disaster emergencies. In the Japanese post-earthquake activities, local governments conduct emergency water deliveries aimed at supplying at least this amount of water. (b) 10-100lpcpd is said to be a minimum requirement to be able to cook foods and prepare daily meals. This level is considered as a target of supply during the second stage of restoration. (c) In the third stage, water supply is aimed at delivering $100-180 l p c p d$, which is not enough for normal activity levels but basic demands are met. (d) Then, finally, normal levels are to be recovered at which water consumption in Japanese urban regions is $200-400 l p c p d$. These four levels may be typically defied as the corresponding service levels, level 0 - level 3, respectively, and corresponding restoration curves for these levels can be drawn as in Figure 9(3). They will be a comprehensive representation of the progress of restoration on the side of the lifeline sector.

While these restoration curves are an engineering measure, the users' perception of lifeline disruption may be represented by the time variation of the degree of acceptance as shown in the lower half of Figure 9(3). People can stand lifeline disruptions for some period immediately following the earthquake. But as a reduced level of supply is sustained, their demand will increase and the individual users' "acceptance curve" decreases with time, and converges to a certain lower level. The speed of decrease and the reduced level of convergence would be different for different service levels. It is emphasized that the acceptance curves should be understood as a measure not only of lifeline users' physical environments but also their psychological situations. Therefore, definition of the acceptance curves must be done on the basis of a rational combination of evaluations both from engineering and social psychology.

Once the restoration curves and the acceptance curves are defined for various service levels, the rate of acceptance, or the "overall acceptance" by the people in the entire service area, denoted by $D(t)$ can be defined as the weighted mean of these curves; i.e.,

$$
D(t)=\frac{\sum_{i} R_{i}(t) A_{i}(t)}{T_{p}}
$$

in which $R_{i}(t)=$ restoration curve at service level $i, A_{i}(t)=$ (individual users') acceptance curve, and $T_{p}=$ duration of the total post-earthquake period. The summation is performed for all supply levels at time $t$.

A schematic illustration of the overall acceptance curve $D(t)$ is given in the right-hand side of Figure 9(3): a single curve that can be used as a comprehensive measure of evaluation of post-earthquake performance of lifeline systems. The area of the section above the overall acceptance curve $D(t)$ and below the horizontal line of unity, denoted by $S_{2}$, may be used as an utility index of lifeline performance incorporating users' evaluation. Applications to actual earthquake disasters are found in Kameda [1994].

\subsection{An Experience in Kobe on Users' Difficulties in Water Shortage}

As we saw in Figure 1, a very long period of time, 82 days, was needed for recovery of water supply in Kobe, 1995. The experience was quite severe if compared to the cases of other earthquakes. For this reason, the time needed for functional restoration played a role of a quantitative index for measuring water customers' difficulties coming from sustained water loss, which are basically qualitative or judgmental issues. An evidence this situation is reflected is seen in the telephone calls from individual customers to the Municipal Water Supply Headquarters that were made throughout the restoration period [Matsushita, 1999b]. 
There were a total of approximately 2,400 calls. The number of calls per day generally decreased with time, as restoration works progressed and the total number of people without water supply decreased. In contrast, the number of calls per day normalized by the number of customers without water remained nearly constant during the first four weeks of restoration period, and increased drastically after four weeks had passed.

This demonstrates that the people who had to spend more than four weeks without water had excessive difficulties of leading their lives. Indeed, the contents of conversation in these calls varied from those of inquirytype in earlier stages to strong complaint, anger and desparation in the post four-week phase. On the basis of this experience, the Kobe Municipal Waterworks Bureau has established a long-term reconstruction plan for its system in a way that emergency recovery to all customers, say the service level 2 as discussed in 4.1, should be finished within four weeks under any heavy urban earthquake disaster. Construction of redundant and robust transmission and distribution networks is the major feature of the reconstruction plan.

The example discussed herein would suggest that quantification of the users' acceptance level can be a feasible concept. By doing so and combining them with engineering technology, it is expected that reasonable framework and methodologies be established for general risk management of lifeline systems under earthquake environment.

\subsection{Development of Consensus on Funding for Disaster Mitigation}

Funding seismic upgrade programs for lifeline systems is a critical issue for executing the programs successfully and complete them within a required period of time. The question is "who pays and how?". An impressive example of resolving this issue is observed in the Seismic Improvement Program for the East Bay Municipal Utility District (EBMUD), California [Diemer, 1998].

As a wholesale agency supporting municipal water supply systems in the East Bay area of the San Francisco Bay Region, EBMUD, serving 1.2 million customers, has an important role of maintaining water supply functions under earthquake emergency. There are two seismogenic active faults crossing its service area: Hayword Fault and Calaveras Fault.

On the basis of experiences of the 1989 Loma Prieta Earthquake, EBMUD began its Seismic Improvement Program, consisting of seismic evaluation, development of improvement strategy, and implementation planning. A 10 year program was established with a total cost of $\$ 189.0$ million. The program is composed of seven stages including reservoir upgrades, pumping plant upgrades, tunnel improvements, construction of a loop pipeline, transmission system upgrades and pipe fault crossings, building upgrades and equipment anchorage, and water treatment plant upgrade.

Besides engineering technologies incorporated in the program, it was a key issue to establish consensus for funding. They needed to find its financial resource by charges on the customers water bills. Extensive procedure was taken for public reach and education. The stakeholders were city councils, planning commissions, neighborhood groups, business groups and associations, service clubs, retiree groups, critical care providers, etc. Through these efforts, a favorable conditions were created, finally to be supportive to a charge of about $\$ 20$ for an average customer per year for the next 30 years.

While technology developments in earthquake engineering is important, their implementation is equally important. Recent urban earthquake disasters continue to give us lessons by letting us notice a simple fact; i.e. earthquake engineering development does not immediately mean that the urban region is safer and more reliable. Implementation is a key factor. Efforts taken for this purpose, such as that introduced herein, should be highly recognized as indispensable steps for realizing safer urban regions.

\section{FUTURE ORIENTATIONS OF EARTHQUAKE ENGINEERING}

\subsection{Generations in Earthquake Engineering Developments}

The history of earthquake engineering development may be outlined as shown in Table 3. Its first generation is represented by static design at elastic limit, the second generation was a movement toward the dynamic design and ductility design as well as liquefaction issues and lifeline earthquake engineering, whose effectiveness was essentially confirmed in the Great Hanshin-Awaji (Kobe) Earthquake Disaster. 
Now, we are in the stage to develop "third generation of earthquake engineering." It should be a comprehensive engineering strategy to incorporate (a) structural and geotechnical mitigation, (b) engineering for crisis management, and (c) systems approach for sustainable developments.

Table 3: Development of earthquake engineering

\begin{tabular}{lc}
\hline Major E.Q, & Development of Earthquake engineering \\
\hline $\begin{array}{l}\text { San Francisco (1906) } \\
\text { Kanto (1923) }\end{array}$ & *Fire following earthquake, Effectiveness of seismic design, Effects of soil \\
Imperial Valley (1940) & $\begin{array}{l}\rightarrow \text { First generation: } \\
\text { Fukui (1948) }\end{array}$ \\
& *(Japan) 1924: Seismic design, Design point at elastic limit \\
& code( $\mathrm{k}=0.2), 1950:$ Building code $(\mathrm{k}=0.1), 1939:$ Highway bridge seismic design \\
& *(USA) 1955: Uniform Building Code \\
\hline
\end{tabular}

Niigata (1964) Era of WCEE (1st: 1956) and technology developments

Tokachi-oki (1968) *Liquefaction, Accumulation of strong motion records; Shear failure of RC columns;

San Fernando (1971) Disruptions of lifeline systems

Miyagiken-oki (1978) $\rightarrow$ Second generation: Dynamic design, Elasto-plastic design points,

Loma Prieta (1989) Countermeasures for liquefaction, Lifeline earthquake engineering

*(Japan) 1971: Enhancement of shear reinforcement (buildings), Dynamic effects and site effects (highway bridges) ; 1973: Chain-type seismic pipeline; 1980-81: Elasto-plastic design standards (building [s =1g]\& RC highway bridges)

*(USA) 1975: AASHTO Interim Bridge Spec, 1978: ATC3, 1981: ATC6, 1983: AASHTO

$\begin{array}{ll}\text { Northridge (1994) } & \text { * } \\ \text { Hyogoken-nanbu } & \text { Complex urban disaster, Near-field strong motion records } \\ \text { (kobe) (1995) } & \text { Third generation comprehensive earthquake engineering: (1) Structural and } \\ & \text { geotechnical mitigation: Near-field ground motion, Nonlinear ground response, } \\ & \text { Permanent ground deformation, Failure mechanism, Structural integrity, Lifeline } \\ & \text { system enhancement, Strategic seismic upgrading of urban infrastructures, } \\ & \text { Performance-based design, Seismic retrofit of existing stocks ; (2) Engineering for } \\ & \text { crisis management: Real-time mitigation, Disaster information management } \\ & \text { systems, Transportation and telecommunication systems, Societal impacts; (3) } \\ & \text { Systems approach for sustainable developments: Technologies for development of } \\ & \text { acceptable risk, Links with environmental issues, Economic analysis and } \\ & \text { assessment }\end{array}$

$\mathrm{K}$ basic design seismic coefficient

$\mathrm{S}$ spectrum for ultimate capacity design

\subsection{Research Initiatives with Multi-disciplinary Integration}

To realize the goal of the third generation earthquake engineering, it is required to promote multi-disciplinary research should be promoted. In the period following the Kobe event, it has been a remarkable trend that "multidisciplinary integration" and "international collaboration" be major keywords. Various efforts have been taken along this direction, which resulted in launching new research initiatives and organizational developments. It is observed that other urban earthquakes such as the Northridge Earthquake have also motivated this.orientation. Following examples are research initiatives conducted on national, bilateral, and multi-lateral bases [Kameda, 1999].

(1)A national project: "Fundamental Studies for the Mitigation of Urban Disasters by Near-Field Earthquakes" (1996-1999FY / Sponsor: Mnistry of Education and Science (MONBUSHO))

* Project PI: Kenzo Toki, Kyoto University/ Co-leader:Tsuneo Okada, Shibaura Institute of Technology

*Designated research projects

A: Strong Motion and Seismic Load

B: Seismic Vulnerability of Urban Facilities and Functions

C: Information and Societal Issues in Crisis Management

(2) A bilateral project: "US-Japan Cooperative Research for Urban Earthquake Disaster Mitigation" (19992003FY / sponsor: MONBUSHO / NSF)

(Japan side organization) 
*Project PI $\square$ Hiroyuki Kameda, Kyoto University

*Coordination Committee Chair: Shunsuke Otani, University of Tokyo

1. Strong Motion and Geotechnical Hazard Assessment

2. Enhancement of Structural Response Performance

3. Advanced Technologies for Improvement of Seismic Performance of Urban Structures

4. High Performance Infrastructure Systems for Destructive Urban Earthquakes

5. Comparative Study on Urban Earthquake Disaster Management

(US side framework : NSF [Liu, Anderson, Astill and Weber, 1997])

*Technical Coordination Committee Chair: Mete A. Sozen, Purdue University

1) Performance-based design and engineering

2) Integrated social science and related multi-disciplinary research

3) Advanced steel structures

4) Geotechnical engineering systems

5) Advanced technologies

(3) A multi-lateral project: "Development of Earthquake and Tsunami Disaster Mitigation Technologies and Their Integration for the Asia-Pacific Region" (1999-2003FY / sponsor: STA)

* Project Leader: Hiroyuki Kameda, EDM and Kyoto Univrsity

* Project Coordinator: Hitoshi Taniguchi, EDM

* Section Leaders: Tetsuo Kubo, EDM/Nagoya Inst. Tech, Fumio Yamazaki, EDM / Univ. of Tokyo, Haruo Hayashi, EDM / Kyoto Univ. \& Hiroyuki Kameda (ditto.)

1. Earthquake Disaster Mitigation Technologies

2. Disaster Risk Assessment and Management

3. Understanding Regional Characteristics of Disasters

4. Master Plan for Earthquake and Tsunami Disaster Mitigation Appropriate to the Asia-Pacific Region

* Counterpart Organizations: from Korea, China, Taipei China, Philippines, Vietnam, Thailand, Singapore, Indonesia, New Zealand, Chile, Mexico, USA, etc.

In these projects, lifeline issues are involved in various ways. For example, in Project (1), part of Section B deals with transportation and telecommunication issues intensively from structural, functional and emergency operation points of view. In Project (2), which has evolved in part from extensive discussion at Project (1)'s Executive Committee meetings, the transportation issue is dealt with on an international basis and with an extended discussion to incorporate socio-economic impacts. In Project (3), water supply - treatment total system will be discussed in the context of risk management and urban diagnosis-prognosis. On this basis, it is expected that a new horizon of lifeline earthquake engineering be developed.

\section{CONCLUSIONS}

The conclusions of this state-of-the-art paper may be summarized as follows.

(1) A historical overview and specific features of lifeline earthquake engineering were presented with an emphasis on a view that 30 year evolution of lifeline earthquake engineering has developed a unique engineering field where issues on a) enhancement of structural performance of individual lifeline components, b) seismic reliability management of lifeline networks, and c) methodological developments for efficient post-earthquake operations constitute major branches and are closely linked.

(2) With a notion that lifeline earthquake engineering practice is based upon systematic combinations of a) upgrading structural performance of network components, b) improvement of network organization, c) implementing system automation, and d) disaster operation under earthquake emergency, lessons from recent urban earthquake disaster, particularly those from Kobe 1995, were reviewed. It was pointed out that despite the huge disaster and many engineering issues that have been raised from the disaster, accomplishments of modern lifeline earthquake engineering played significant roles under the disaster emergency.

(3) It was pointed out that reconstruction of lifeline systems from the disaster is an opportunity for realizing better social infrastructure. Examples were presented as to structural system design of elevated highways, environmental treatment of highways, and network enhancement of water supply systems.

(4) New trends of seismic code developments for lifeline systems have been addressed with an emphasis on a) incorporating near-field ground motions using scenario earthquake-based simulation technique to account for "low probability - high impact load," b) performance-based design methodologies are being pursued, and c) inelastic deformation, plastic displacement, and inelastic strain due to large ground deformation are considered commonly. Typical examples were introduced: water supply systems and railway structures.

(5) System interaction issues under earthquake emergency were addressed. Problem definition and an analytical framework for risk assessment under lifeline system interactions was illustrated. 
(6) Quantification of qualitative issues that are essential in lifeline seismic risk management was discussed. The problem was formulated in terms of users' acceptance levels, and a scheme of evaluation was proposed. Two practical examples that are pertaining to the issue were introduced: a) water customers' voice under emergency in Kobe, and b) public relations policy for funding a seismic improvement program in California.

(7) Future orientations of earthquake engineering was discussed, and "third generation earthquake engineering" was proposed to be a comprehensive framework for disaster risk management incorporating a) structural and geotechnical mitigation, b) engineering for crisis management, and c) systems approach for sustainable developments. Importance of multi-disciplinary research initiative for realizing this goal was emphasized. In this context, lifeline earthquake engineering issues were discussed.

\section{REFFERENCES}

Diemer, D. M. (1998), "Anti-seismic measures on water supply in California," Proceedings of the IWSA International Workshop on Anti-Seismic Measures on Water Supply, Tokyo pp.1-21.

Duke, C.M. and Moran, D.F. (1975), "Guidelines for evolution of lifeline earthquake engineering," Proceedings of the U.S. National Conference on Earthquake Engineering, Michigan, pp367-376.

Hou, Z., Hu, Yuxian, Takada, S. and Wang, L. R. L. (1990, 1994, 1998), series of the Proceedings of ChinaJapan/ China-Japan-US Symposia on Lifeline Earthquake Engineering.

Isoyama R., Iwata, T. and Watanabe, T., (1985), "Optimization of post-earthquake restoration of city gas systems," Proceedings of the Trilateral Seminar-Workshop on Lifeline Earthquake Engineering, Taipei, pp.317.

Irikura, K. (1998), "Prediction of strong motions from future earthquakes in the Osaka basin," The Effects of Surface Geology' on Seismic Motion, A. A. Balkema, Rotterdam, pp.171-188.

JSCE ( Japan Society of Civil Engineers ) (1996a), Proposal on earthquake resistance for civil engineering structures.

JSCE ( Japan Society of Civil Engineers, Committee of Earthquake Engineering ) (1996b), The 1995 Hyogokennanbu Earthquake-investigation into damage to civil engineering structures.

JWWA (Japan Water Works Association) (1997), Seismic Design and Construction Guidelines for Water Supply Facilities - 1997 (in Japanese); English translation of Chapters 1 and 2 (general framework and basic theory) published in 1998.

Kameda, H. and Takada, S., (1991), "Efficient information processing incorporating the system interactions of lifelines under urban earthquake: Part 1," Proceedings of the 3rd US-Japan Workshop on Urban Earthquake Hazards Reduction, Honolulu.

Kameda, H. and Nojima, N (1992), "Developments of lifeline earthquake engineering," Proceedings of the IDNDR Symposium on Earthquake Disaster Reduction Technology, Tsukuba, IISEE, Building Research Institute, pp111-128.

Kameda, H. (1994), "Multi-phase evaluation of lifeline system performance under earthquake environment," Keynote Lecture, Proceedings of the 2nd China-Japan-US Trilateral Symposium on Lifeline Earthquake Engineering, Xian, pp.1-16.

Kameda. H., and Hamada, M. (1998), "Engineering management of civil infrastructures in Japan following the 1995 Hyogoken-nanbu (Kobe) Earthquake," CD-ROM Proceedings of the 11th European Conference on Earthquake Engineering, Paris, September 6-11, 1998, Session TS3.

Kameda, H. (1999) "Recent developments and research initiatives for urban earthquake disaster mitigation," Keynote Address, Proceedings of the 6th Japan/United States Workshop on Urban Earthquake Hazard Reduction, ISSS/EERI, Kobe, pp.17-30.

Katayama, T. (1991), "Lifeline earthquake engineering in Japan a state-of-the-art," Proceedings of the 3rd U.S. Conference, TCLEE/ASCE, Lifeline Earthquake Engineering, Los Angeles, pp17-32.

Kubo, K. and Jennings, P.C., Ed. (1976), Proceeding of US-Japan Seminar on Earthquake Engineering Research with Emphasis on Lifeline Systems, Tokyo.

Kubo, K. and Shinozuka, M., Ed., (1981), Proceedings of Review Meeting of US-Japan Cooperative Research on Seismic Risk Analysis and Its Application to Reliability-Based Design of Lifeline Systems. 
Liu, S. C., Anderson, W., Astill, C., and Weber, L. (1997), "The NSF earthquake disaster mitigation research program," Proceedings of International Symposium on Natural Disaster Prediction and Mitigation, Kyoto, organized by DPRI, Kyoto University, pp.65-71.

Matsushita, M. (1999a), "The 1995 Kobe Earthquake and the new JWWA seismic design guideline for water facilities," Proceedings of the 7th US/Japan Workshop on Seismic Resistant Design of Lifeline Facilities and Countermeasures Against Liquefaction, Seattle.

Matsushita, M. (1999b), "Restoration process of Kobe water system from the 1995 Hanshin-Awaji Earthquake," Proceedings of the 5th U.S. Conference on Lifeline Earthquake Engineering, Seattle, pp.978-987.

Nishimura, A. (1999), "Summary of the earthquake resistant design standards for railway structure," Proceedings of the 7th US/Japan Workshop on Seismic Resistant Design of Lifeline Facilities and Countermeasures Against Liquefaction, Seattle.

NIST (National Institute for Standards and Technologies, USA) (1984, 1992, 1997), series of the Proceedings of the 1st, 4th and 7th U.S.-Japan Workshops on Earthquake Disaster Prevention for Lifeline System.

Nojima, N., Kameda, H. and Shinozuka, M. (1990), "Fundamental structure of earthquake disaster countermeasures in lifelines," Journal of Natural Disaster Science, Vol.12, No.1, pp29-47.

Nojima, N. and Kameda, H., (1992), "Optimal strategy by use of tree structure for post-earthquake restoration of lifeline network systems," Proceedings of the 10th World Conference on Earthquake Engineering, Madrid, Vol.10, pp.5541-5546.

Nojima, N. and Kameda, H. (1996), "Lifeline interactions in the Hanshin-Awaji Earthquake Disaster," The 1995 Hyogoken-Nanbu Earthquake - Investigation into Damage to Civil Engineering Structures -, Japan Society of Civil Engineers, June 1996, pp.253-264.

O'Rourke, T. D. and Hamada, M. (editors) (1988, 1989, 1991, 1992, 1994, 1996, 1999), series of the Proceedings of the US-Japan / Japan-US Workshops on Earthquake Resistant Design of Lifeline Facilities and Countermeasures against Soil Liquefaction.

PWRI (Public Works Research Institute, Japan) (1984, 1989, 1992, 1995), series of the Proceedings of the 2nd, $3 r d$, 5th and 6th U.S.-Japan Workshops on Earthquake Disaster Prevention for Lifeline Systems, Tsukuba.

RTRI (Railway Technical Research Institute) (1999), Earthquake Resistant Design Standards for Railway Structures and Commentaries, Maruzen, Tokyo (in Japanese).

Sun, S. (1993), "Seismic damage of lifeline facilities and disaster prevention in China," Proceedings of the IDNDR Aichi/Nagoya International Conference, Nagoya, pp203-211.

TCLEE/ASCE $(1977,1981,1991,1995,1999)$, series of the Proceedings of the U.S. Conference on Lifeline Earthquake Engineering. 